\title{
Hand Grip Strength and Self-Perceptions of Physical Attractiveness and Psychological Well-Being
}

\author{
Michael Sneade $^{1}$ Adrian Furnham ${ }^{1,2}$
}

Published online: 20 January 2016

(C) Springer International Publishing 2016

\begin{abstract}
This study investigated the link between handgrip strength and self-rated physical attractiveness, sexual history, and social characteristics in 145 male university students. Handgrip strength correlated with both height and weight, as well as self-perceived happiness, health, social confidence overall physical attractiveness, and overall number of sexual partners. It also correlated with self-assessed physical fitness levels and there was a predictable link between handgrip strength and age of first sexual intercourse. It is argued that handgrip strength is an indicator of both genetic quality and developmental health. Limitations of the study are acknowledged.
\end{abstract}

Keywords Handgrip strength $\cdot$ Attractiveness $\cdot$ Fitness

\section{Introduction}

There is a large and growing literature on handgrip strength (HGS) which correlates with health status in the general adult population (Cheung et al. 2013). Low HGS also correlates with poor overall muscle strength, limits in anatomical function, and disability (Rantanen et al. 2003; Guimaraes et al. 2007). On the other hand, high HGS correlates with positive attributes in body composition, shape, and dimension; levels of fat-free (FFM) body mass, muscle mass (Sartorio et al. 2002; Shoup and Gallup 2008), muscle/physical function

Adrian Furnham

a.furnham@ucl.ac.uk

1 Research Department of Clinical, Educational and Health Psychology, University College London, London, UK

2 Norwegian Business School (BI), Nydalveien, Olso, Norway
(Arroyo et al. 2007), strength (Aadahl et al. 2011); fitness levels of college-age males (Gallup et al. 2007; Shoup and Gallup 2008); bone mineral density (Chan et al. 2008); disability in older men (Giampaoli et al. 1999); as well as the attractiveness and assertiveness of an individual's dancing ability (Hugill et al. 2009).

HGS scores in humans are associated with environmental influences and a genetic component. Developing factors such as exercise, day-to-day activity levels, nutrition, and health issues all affect and influence one's HGS (Kuh et al. 2006; Norman et al. 2011). An individual's HGS score also has an inherited constituent. A correlation coefficient $(r)$ of .30 has been shown within twin studies (Arden and Spector 1997), with correlation becoming increasingly significant after adjusting for the effects of age, weight, height, frame size, and various anthropometric factors between siblings (Frederiksen et al. 2002). These correlations are present for both sexes but stronger in males. Men in general give higher readings than women of the same age (Mitsionis et al. 2009) and also show a greater percentile decline due to aging, especially after the age of 30 (Vianna et al. 2007).

Some correlates of HGS, such as the number of fathered children has not been investigated, nor the relationship between HGS and self-rated attractiveness. We assume that HGS is a simple, but reliable, index of fitness. Males with more "wedge-shaped" shoulder-to-hip ratios are rated as more facially attractive by females (Shoup and Gallup 2008). Men with narrow hips, medium to high levels of musculature and broad, wide shoulders are seen as preferable (e.g., Dixson et al. 2003; Hughes and Gallup 2003; Fan et al. 2005). This study investigates HGS and self-rated attractiveness in healthy young males.

Fitness levels in males are the product of various anatomical and physiological factors; muscle strength and endurance, body composition, cardiorespiratory output etc. (Calvo et al. 
2002; Ortega et al. 2008). HGS has thus been shown to be related to reproductive success, dominant behavior, physical performance, and sexual function (Atkinson et al. 2012; Gallup et al. 2009; Page et al. 2005).

From an evolutionary perspective, individuals expressing greater levels of physical fitness would excel at certain essential tasks; hunting, fighting rivals etc. which would give them an advantage over their peers (Lukaszewski et al. 2014). Physical health has been shown to be a marker of general well-being which is in itself attractive to mates (Brief et al. 1993). It has been suggested that a key role of an individual's body attractiveness is to signal their level of personal fitness (Hönekopp et al. 2007). There are many established body markers of attractiveness which indicate health like body and facial symmetry, facial sexual dimorphism, leg-to-body ratio, foot size etc. (Shackelford and Larsen 1999; Swami and Furnham 2008). Amongst the most investigated are waist-to-hip ratio and upper body muscularity in men (Swami and Furnham 2007).

We tested two hypotheses based on the above literature: (H1) HGS would be significantly positively correlated with a number of dimensions of self-rated attractiveness (body shape, health, physical attractiveness); (H2) HGS would be correlated with age of first sexual intercourse and current sexual activity.

\section{Method}

\section{Participants}

All 145 participants were male current students studying at a British University. They ranged in age from 18 to 32 (mean $=21.54, S D=2.71)$. Their self-reported mean height was $180.16 \mathrm{~cm}(S D=6.74)$ and weight was $74.66 \mathrm{Kg}$ $(S D=9.84)$. They reported their age of first intercourse to be 17.53 years $(S D=5.37)$ and number of sexual partners 6.80 $(S D=8.83)$. Of the 145, four classed themselves as homosexual, three preferred not to provide data on their sexuality, while the remaining 138 were heterosexual. Of the 145 who took part in the study, 17 were left-hand dominant, 124 were right hand-dominant, and four did not provide details on their dominant-hand preference.

\section{Measuring Hand Grip Strength}

To measure HGS we used a hand-held dynamometer (Camry Electronic Hand Dynamometer EH101-37). The participants were told to hold the dynamometer in their dominant hand. On instruction they were required to squeeze the dynamometer as hard as possible, giving maximum isometric effort for 3-5 s. The participants were not allowed to move the position of the arm or any body part during the trial. Following a practice attempt, three trials were attempted with each participant. Between 30 and $40 \mathrm{~s}$ rest given between attempts to account for muscle fatigue. The maximum value obtained was used for analysis. The mean was $45.83 \mathrm{Kg}(S D=8.90)$ and the range 25.50 to 71.70 .

\section{Questionnaire}

Participants were asked to complete a two-part anonymous survey. The first part included questions on height and weight; age, ethnic background, dominant hand, sexual orientation, their university year and program; the number of sexual partners, and age of first sexual intercourse. The second part of the study required the participant to anonymously rate themselves on Likert scale eight questions (shown in Table 1) designed and piloted for this study. They were taken from numerous studies on attractiveness (Swami and Furnham 2008). Pilot work suggested that they were easy to understand and there were no floor or ceiling effects. The Cronbach's alpha for the scale was .83 .

\section{Procedure}

Participants were approached by the first author on campus before and after lectures. They were students of all disciplines but more science than arts students. Because they were assured the task was anonymous and would take less than $10 \mathrm{~min}$ most agreed to take part. All participants were screened prior to taking part. Questions included recent physical activity and injury prior to taking part. Those who had physically exerted themselves in the past $24 \mathrm{~h}$; for example had been to the gym, kayaking etc. were excluded from participating, as were those who classed themselves as physically impaired through injury or disability. Ethical approval was sought and received for this study.

\section{Results}

Because some responses, namely number of sexual partners and age of first intercourse, was not normally distributed they were $\log$ transformed.

\section{Correlations}

As expected HGS correlated significantly with both height $(r=.38, p<.001)$ and weight $(r=.43, p<.001)$, consistent with previous studies, and BMI $(r=.42, p<.001)$. There was also a correlation between height and weight $(r=.57$, $p<.001)$. Maximum HGS did not correlate with age $(r=.11$, $p=.21)$ and number of sexual partners since starting university $(r=.16)$ but it did correlated significantly with self-reported life-time number of sexual partners $(r=.22, p<.05)$. There 
Table 1 Means and SDs for the eight questions and the results from the Varimax rotated factor analysis and principal component analysis

\begin{tabular}{|c|c|c|c|c|c|c|}
\hline & \multirow[t]{2}{*}{ Mean } & \multirow[t]{2}{*}{$S D$} & \multicolumn{2}{|c|}{ Varimax } & \multicolumn{2}{|c|}{ PCA } \\
\hline & & & 1 & 2 & 1 & 2 \\
\hline Q4. How attractive is your overall body shape? & 6.60 & 1.31 & .87 & .30 & .75 & -.44 \\
\hline Q6. How attractive is your body composition? & 6.43 & 1.44 & .83 & .20 & .68 & -.50 \\
\hline Q5. How content are you with your bodyweight? & 7.15 & 1.58 & .76 & .24 & .64 & -.40 \\
\hline Q7. How physically fit would you rate yourself? & 6.56 & 1.49 & .73 & .54 & .78 & -.10 \\
\hline Q2. Generally, how socially confident are you? & 7.05 & 1.26 & .17 & .86 & .58 & .67 \\
\hline Q1. How happy are you on a day-to-day basis? & 7.09 & 1.17 & .22 & .79 & .57 & .55 \\
\hline Q8. How is your general health? & 7.42 & 1.47 & .49 & .75 & .73 & .29 \\
\hline $\begin{array}{l}\text { Q3. Overall, how physically attractive would } \\
\text { you rate yourself? }\end{array}$ & 6.69 & 1.24 & .58 & .66 & .74 & .13 \\
\hline Eigenvalue & & & 3.77 & 1.45 & & \\
\hline Variance & & & 47.13 & 18.12 & & \\
\hline
\end{tabular}

Italicised number represent those loading most highly on the different factors was also a significant correlation with HGS and age of first intercourse $(r=-.26, p<.05)$ indicting those with greater HGS had intercourse at an earlier age. When partial correlations were run between the normalized scores for number of

Table 2 First regression with grip strength as criterion and individual questions as predictors

$\begin{array}{ll}\begin{array}{l}\text { Unstandardized } \\ \text { regression }\end{array} & \begin{array}{l}\text { Standardized } \\ \text { regression } \\ \text { coefficient (B) }\end{array} \\ & (\beta) \\ & \text { coefficient }\end{array}$

\begin{tabular}{llll}
\hline Model 1 & & & \\
Age & .20 & .06 & .74 \\
Height & 26.17 & .20 & $2.13^{*}$ \\
& 10.26 & .29 & $3.03^{* *}$ \\
Wei- & & & \\
ght & & & \\
Model 2 & & .09 & 1.27 \\
Age & .31 & .08 & .88 \\
Height & 10.20 & .22 & $2.34^{*}$ \\
& .20 & & \\
Wei- & & .14 & 1.55 \\
ght & 1.05 & .10 & 1.01 \\
Q1 & .68 & .20 & $2.12^{*}$ \\
Q2 & 1.47 & -.15 & -1.35 \\
Q3 & -1.01 & -.07 & -.75 \\
Q4 & -.39 & .06 & .65 \\
Q5 & .38 & -.05 & .48 \\
Q6 & -.29 & 0.29 & $2.95^{* *}$ \\
Q7 & 1.79 & & \\
Q8 & & & \\
\hline
\end{tabular}

Model $1 ; F(3,131)=10.70^{* * *}$ Adj $R^{2}=18 \%$

Model $2 ; F(11,123)=8.04 * * *$ Adj $R^{2}=37 \%$

$* p<.05 * * p<.01 * * * p<.001$ sexual partners overall and since being at university controlling for height and weight both were non-significant $(r=.17$, $r=.12$ ). Thus, $\mathrm{H} 2$ received partial support.

However HGS correlated significantly with how happy the participant perceived themselves to be $(r=.43)$, how socially confident they rated themselves $(r=.47)$, their self-rated overall physical attractiveness $(r=.42)$, their physical fitness $(r=.27)$, and their self-assessed health $(r=.44)$. There was also significant correlation between those who rated themselves as more socially confident with both height $(r=.30)$ and weight $(r=.34)$. Partial correlations were then computed between HGS and self-ratings partialling out height and weight: there was still a strong significant correlation between HGS and self-rated social confidence $(r=.37)$ and physical attractiveness $(r=.36)$.

Participants who reported a greater number of sexual partners also rated themselves as increasingly socially confident $(r=.33)$, more physically attractive $(r=.31)$, viewed themselves with a more attractive body composition $(r=.20)$, and rated themselves with greater levels of physical fitness $(r=.19)$. This provides support for H1. It is worth noting that none of the variables correlated significantly with age of first sexual intercourse.

\section{Factor Analysis}

The eight question ratings were then treated to a principal component analysis (PCA) as well as two (Varimax and Oblimin) rotated factor analysis. All yielded two factors with both rotations being very similar. Two factors were extracted (using the scree test) in the Varimax analysis which accounted for a total of $65.3 \%$ of total variance in the sample. Table 1 shows the result of the factor analysis using a cut-off score of .60. The first factor referred more to physical factors and the second to social factors associated with physical 
attractiveness, though there was some ambiguity. The two factors in the PCA showed the first two questions loaded on the first factor "How happy are you on a daily basis" and "Generally, how socially confident are you?" while all others loaded on the second factor which was a clearer distinction between general and physical factors. Table 1 also shows the results of the PCA.

Using the Varimax derived factors, there was positive correlation between the first factor score and number of sexual partners $(r=.22)$. There were also significant correlations between the second factor and HGS $(r=.57)$, height $(r=.34)$, weight $(r=.34)$ and number of sexual partners $(r=.28)$. For the PCA derived factors, the first general factor correlated positively with number of sexual partners overall $(r=.22)$ and since being at university $(r=.21)$ with similar results for the second more physical factor $(r=-.25$ and $r=.20)$.

\section{Regressions}

Two regressions were performed (Table 2). In model 1, height $(\beta=.20, p=.035)$ and weight $(\beta=.29, p=.003)$ were both significant predictors of HGS. In model 2 , weight $(\beta=.22$, $p=.02)$, self-assessed levels of overall physical attractiveness $(\beta=.20, p=.04)$, and general health $(\beta=.29, p=.004)$ were all significant influencers of HGS. Further to this, model 1 is not only significant but predicts for $17.8 \%$ of variance seen in the dependent variable, HGS. model 2 is again significant, predicting for $36.6 \%$ of variance seen in HGS.

In the second regression shown in Table 3, model 1 showed height $(\beta=.21, p=.029)$ and weight $(\beta=.29, p=.003)$ both provide significant effect on HGS scores. In model 2 , weight $(\beta=.02, p=.028)$ and factor score $2(\beta=.48, p<.001)$ were all significant influencers of HGS. Model 1 was significant and

Table 3 Second regression with grip strength as crirterion and factor scores as predictors

\begin{tabular}{lll}
$\begin{array}{l}\text { Unstandardized } \\
\text { regression } \\
\text { coefficient (B) }\end{array}$ & $\begin{array}{l}\text { Standardized } \\
\text { regression } \\
\text { coefficient } \\
(\beta)\end{array}$ \\
\hline
\end{tabular}

\begin{tabular}{llll}
\hline Model 1 & & & \\
;Height & 26.96 & .21 & $2.21^{*}$ \\
Weight & .26 & .29 & $3.08^{* *}$ \\
Model & & & \\
2 & & & \\
Height & 12.88 & .10 & 1.15 \\
Weight & .18 & .19 & $2.22^{*}$ \\
Factor 1 & -.21 & -.02 & -.31 \\
Factor 2 & 4.21 & .48 & $5.97^{* *}$ \\
\hline
\end{tabular}

Model $1 ; F(2,132)=15.832 * * *$ Adj $R^{2}=18 \%$

Model $2 ; F(4,130)=19.918^{* * *}$ Adj $R^{2}=36 \%$

${ }^{*} p<.05 ; * * p<.01 ; * * * p<.001$ predicted $18.1 \%$ of the variance seen in HGS, this variance can be accounted for through predictor variables height and weight. Model 2 was significant, the predictors height, weight, and factors 1 and 2, obtained through factor analysis, predicted $36.1 \%$ of the observed variance.

Various other regressions were performed. First a similar analysis was done to that in Table 3 except the factor scores were from the PCA analysis. The regression was significant $(F(4130)=16.22, p<.001)$ and which accounted for $31 \%$ of the variance. Only the first general factor was a significant predictor $(\beta=.18, p<.001)$. The eight question scores were then totalled for another regression which was significant $(F(3131)=17.79, p<.001)$ and which accounted for $27 \%$ of the variance. The overall rating was significant $(\beta=.33$, $p<.001)$.

Finally a stepwise multiple regression was run with the totalled well-being score from the eight questions as the criterion variable. In the first step, participant age, height, and weight were entered and in the second step the HGS score. The results from the second step $(F(4130)=8.22, p<.001)$ showed that two variables were significant namely height $(\beta=.27, p<.001)$ and HGS $(\beta=.42, p<.001)$ and that HGD increased the amount of variance accounted for from 7 to $18 \%$. This suggests that HGS accounts for more variance than shape to overall self-rated general and physical well-being.

\section{Discussion}

As anticipated, HGS correlated with various anatomical measurements and self-rated traits. There was significant correlation with weight; and a moderate, significant relationship with height (Sartorio et al. 2002). As in other studies (see Gallup et al. 2007 etc.), we did find a significant association between maximum HGS and number of sexual partners, and also with age of first intercourse.

It is worth noting that some (57\%) of the participants lost their virginity between the ages of 16-18. It could be that mean age of participant was too low (mean $=21.5$; $S D \pm 2.70$ ), especially in relation to the average age of first sexual experience (mean $=17.5 ; S D \pm 5.40$ ), thus limiting the epoch in which sexual activity could occur. Also, a possibility could be that the participants simply lied on the questionnaire; although anonymous, there could possibly be underlying motives to falsify responses. This is always a problem with males reporting sexual activity.

There were significant correlations between HGS and how happy individuals rate themselves, their levels of social confidence, self-rated overall physical attraction, and general health. There was a weaker association between HGS and perceived levels of physical fitness. For all significant variables, HGS correlates more strongly than height or weight alone. This would indicate that HGS is a better 
indicator of these traits than these individual anatomical measures. Indeed this supports the work of Gallup et al. (2009) who have shown that HGS differs from other measures like BMI in predicting social and psychological outcomes. They argue that HGS is a strong correlate and indicator of physical prowess, vitality, and social ability in young males.

It is interesting to note that in the final regression height rather than weight was a predictor of the overall self-rated score. It is generally believed that taller people are seen to be more attractive and persuasive. Recent studies have hoped to confirm this suggestion, with Judge and Cable (2004) assessing the impact of height on success at work and salary. They suggest firstly that height is related to social esteem or the status ascribed to individuals. Secondly, that height predicts self-esteem, impacting adjustment. This is linked to the belief that taller people are treated with more so respect than their shorter peers, resulting in the increase of self-confidence in a self-fulfilling pattern.

Levels of perceived social-confidence correlate strongly with HGS. The reason for this strong association could be the result of many factors. One of these is that HGS is related to height, weight, strength etc. (Sartorio et al. 2002; Arroyo et al. 2007; Shoup and Gallup 2008). It has been shown that not only are muscular and toned bodies associated with confidence and power in social situations (Grogan 2002), but that muscularity is viewed positively, and there is a continued positive association seen between confidence and muscularity (Morrison and Morrison 2006). In short, muscularity and fitness are seen as highly attractive to females who are more likely to mate with physically strong and healthy males (Swami and Furnham 2008).

With regard to testosterone's role in social dominance (see Rowe et al. 2004 etc.), and the apparent relationship between HGS and social dominance, it seems that those larger in physical size, exhibiting greater HGS scores would see themselves as more socially confident. This finding is in keeping with the proposed evolutionary concept of resource holding power (RHP) in which individuals evaluate the fighting ability of their opponent with regards to their own. Outcomes of disputes are not always decided by all-out aggression and conflict, but rather by the available fitness budget that each individual is willing to expend, with regard to a resource (Sell et al. 2009). Within the animal kingdom, physical size is believed to be a reliable gauge of an individual's RHP and this translates over into human conflict (Archer and Benson 2007; Archer and Thanzami 2009). Indeed Sell et al. (2009) empirically demonstrated that face and body appearance gives a very accurate indication of a person's fighting ability and strength.

The two major limitations to this study are the small number of participants, and that the data gathered on attractiveness, fitness levels, health, and height/weight being self-rated. It would be desirable to have a much larger population group with a wider age range and having actual measures of height and weight, as well as HGS and even other measures of fitness like blood-pressure; that is fitness/health levels gathered from medical records and from preforming physical assessments. Moreover, it would be desirable to have observer ratings of attractiveness and social skill by those who know the participants to supplement self-reports. However, this study does attest to the predictive power of a very simple to measure index of fitness namely HGS.

Compliance with Ethical Standards Ethical approval was sought and received for this study.

\section{References}

Aadahl, M., Beyer, N., Linneberg, A., \& Thuesen, B. (2011). Grip strength and lower limb extension power in 19-72 year-old Danish men and women: the health 2006 study. Journal of Gerontology, 60, 224-231.

Archer, J., \& Benson, D. (2007). Physical aggression as a function of perceived fighting ability and provocation: an experimental investigation. Aggressive Behaviour, 34, 9-24.

Archer, J., \& Thanzami, V. (2009). The relation between mate value, entitlement, physical aggression, size and strength among a sample of young Indian men. Evolution and Human Behaviour, 30, 315321.

Arden, N. K., \& Spector, T. D. (1997). Genetic influences on muscle strength, lean body mass, and bone mineral density: a twin study. Journal of Bone and Mineral Research, 12, 2076-2081.

Arroyo, P., Lera, L., Sanchez, H., Bunout, D., Santos, J. L., \& Albala, C. (2007). Anthropometry, body composition and functional limitations in the elderly. Revista Medica de Chile, 135, 846-854.

Atkinson, J., Pipitone, R. N., Sorokowska, A., Sorokowski, P., Mberira, M., Bartels, A., \& Gallup, G. G., Jr. (2012). Voice and handgrip strength predict reproductive success in a group of indigenous African females. PloS one, 7(8), e41811.

Brief, A. P., Butcher, A. H., George, J. M., \& Link, K. E. (1993). Integrating bottom-up and top-down theories of subjective well-being: the case of physical health. Journal of Personality and Social Psychology, 64, 646-653.

Calvo, M., Rodas, G., Vallejo, M., Estruch, A., Arcas, A., \& Javierre, C. (2002). Heritability of explosive power and anaerobic capacity in humans. European Journal of Applied Physiology, 86, 218-225.

Chan, D. C. C., Lee, W. T. K., Lo, D. H. S., Leung, J. C. S., Kwok, A. W. L., \& Leung, P. C. (2008). Relationship between grip strength and bone mineral density in healthy Hong Kong adolescents. Osteoporosis International, 19, 1485-1495. 86, 218-225.

Cheung, C., Nguyen, U., Au, E., Tan, K., \& Kung, A. (2013). Association of handgrip strength with chronic diseases and multi-morbidity: a cross-sectional study. Age, 35, 929-941.

Dixson, A., Halliwell, G., East, R., Wignarajah, P., \& Anderson, M. (2003). Masculine somatotype and hirsuteness as determinants of sexual attractiveness to women. Archives of Sexual Behaviour, 32, 29-39.

Fan, J., Dai, W., Liu, F., \& Wu, J. (2005). Visual perception of the male body attractiveness. Proceeding of the Royal Society London, 272, 219-226.

Frederiksen, H., Gaist, D., Petersen, H., Hjelmborg, J., McGue, M., Vaupel, J., \& Christensen, K. (2002). Hand grip strength: a phenotype suitable for identifying genetic variants affecting mid- and latelife physical functioning. Genetic Epidemiology, 23, 110-122. 
Gallup, A., White, D., \& Gallup, G., Jr. (2007). Handgrip strength predicts sexual behavior, body morphology, and aggression in male college students. Evolution and Human Behavior, 28, 423-429.

Gallup, A. C., O'Brien, D. T., White, D. D., \& Wilson, D. S. (2009). Handgrip strength and socially dominant behavior in male adolescents. Evolutionary Psychology, 8, 229-243.

Grogan, S. (2002). Body image focus groups with boys and men. Men and Masculinity, 4, 219-232.

Giampaoli, S., Ferrucci, L., Cecchi, F., Lo Noce, C., Poce, A., Dima, F., \& Menotti, A. (1999). Hand-grip strength predicts incident disability in non-disabled older men. Age and Ageing, 28, 283-288.

Guimaraes, A., Carlsson, G., \& Marie, S. (2007). Bite force and handgrip force in patients with molecular diagnosis of myotonic dystrophy. Journal of Oral Rehabilitation, 34, 195-200.

Hönekopp, J., Rudolph, U., Beier, L., Liebert, A., \& Müller, C. (2007). Physical attractiveness of face and body as indicators of physical fitness in men. Evolution and Human behaviour, 28, 106-111.

Hughes, S., \& Gallup, G. (2003). Sex differences in morphological predictors of sexual behaviour: shoulder to hip and waist to hip ratios. Evolutionary and Human Behaviour, 24, 173-78.

Hugill, N., Fink, B., Neave, N., \& Seydel, H. (2009). Men's physical strength is associated with women's perceptions of their dancing ability. Personality and Individual Differences, 47(5), 527-530.

Judge, T., \& Cable, D. (2004). The effect of physical height on workplace success and income. Journal of Applied Psychology, 89, 428-441.

Kuh, D., Hardy, R., Butterworth, S., Okell, L., Wadsworth, M., Cooper, C., \& Sayer, A. (2006). Developmental origins of midlife grip strength: findings from birth cohort study. Journal of Gerontology, 61, 702-706.

Lukaszewski, A. W., Larson, C. M., Gildersleeve, K. A., Roney, J. R., \& Haselton, M. G. (2014). Condition-dependent calibration of men's uncommitted mating orientation: evidence from multiple samples. Evolution and Human Behavior, 35, 319-326.

Mitsionis, G., Pakos, E., Statilas, K., Paschos, N., Papakpstas, T., \& Beris, A. (2009). Normative data on hand grip strength in a Greek adult population. International Orthopaedics, 33, 713-717.

Morrison, T., \& Morrison, M. (2006). Psychometrics properties of the Swansea Muscularity Attitudes Questionnaire (SMAQ) (pp. 131144).
Norman, K., Stobäusc, N., Gonzalez, C., Schulzke, J., \& Pirlich, M. (2011). Hand grip strength: outcome predictor and marker of nutritional status. Clinical Nutrition, 30, 135-142.

Ortega, F., Ruiz, J., Castillo, M., \& Sjöström, M. (2008). Physical fitness in childhood and adolescence: a powerful marker of health. International Journal of Obesity, 32, 1-11.

Page, S. T., Amory, J. K., Bowman, F. D., Anawalt, B. D., Matsumoto, A. M., Bremner, W. J., \& Tenover, J. L. (2005). Exogenous testosterone (T) alone or with finasteride increases physical performance, grip strength, and lean body mass in older men with low serum $\mathrm{T}$. Journal of Clinical Endocrinology \& Metabolism, 90, 1502-1510.

Rantanen, T., Volpato, S., Ferrucci, L., Heikkinen, E., Fried, L., \& Guralnik, J. (2003). Handgrip strength and cause-specific and total mortality in older disabled women: exploring the mechanism. Journal of the American Geriatrics Society, 51, 636-641.

Rowe, R., Maughan, B., Worthman, C. M., Costello, E. J., \& Angold, A. (2004). Testosterone, antisocial behavior, and social dominance: pubertal development and biosocial interaction. Biological Psychiatry, $55,546-552$.

Sartorio, A., Lafortuna, C., Pogliaghi, S., \& Trecate, L. (2002). The impact of gender, body dimension and body composition on hand-grip strength in healthy children. Journal of Endocrinological Investigation, 25, 431-435.

Sell, A., Cosmides, L., Tooby, J., Sznycer, D., von Rueden, C., \& Gurven, M. (2009). Human adaptations for the visual assessment of strength and fighting ability from the body and face. Proceedings of The Royal Society, 276, 575-584.

Shackelford, T. K., \& Larsen, R. J. (1999). Facial attractiveness and physical health. Evolution and Human Behavior, 20, 71-76.

Shoup, M. L., \& Gallup, G. G., Jr. (2008). Men's faces convey information about bodies and their behaviour: what you see is what you get. Evolutionary Psychology, 6, 469-479.

Swami, V., \& Furnham, A. (2008). The psychology of physical attractiveness. London: Routledge.

Swami, V., \& Furnham, A. (Eds.). (2007). The body beautiful. Basingstoke: Palgrave Macmillan.

Vianna, L. C., Oliveira, R. B., \& Araujo, C. G. (2007). Age-related decline in handgrip strength differs according to gender. Journal of Strength and Conditioning Research, 21, 1310-1314. 